\title{
The effects of a telephone-based orientation program, delivered during the waiting time, on anxiety in patients undergoing coronary angiography
}

Follow this and additional works at: https://www.journal.acorn.org.au/jpn

Part of the Perioperative, Operating Room and Surgical Nursing Commons

\section{(c) (i)}

This work is licensed under a Creative Commons Attribution 4.0 License.

\section{Recommended Citation}

Shahpari, Maryam; Heidari, Shahin; and Sadeghi, Tabandeh (2021) "The effects of a telephone-based orientation program, delivered during the waiting time, on anxiety in patients undergoing coronary angiography," Journal of Perioperative Nursing: Vol. 34 : Iss. 1 , Article 1.

Available at: https://doi.org/10.26550/2209-1092.1102

https://www.journal.acorn.org.au/jpn/vol34/iss1/1

This Article is brought to you for free and open access by Journal of Perioperative Nursing. It has been accepted for inclusion in Journal of Perioperative Nursing by an authorized editor of Journal of Perioperative Nursing. 


\section{The effects of a telephone-based orientation program, delivered during the waiting time, on anxiety in patients undergoing coronary angiography}

\section{Cover Page Footnote}

Acknowledgements This study was extracted from a student's thesis (code: 20/1/97326) approved by Rafsanjan University of Medical Sciences. Hereby, we extend our gratitude to the authorities of the university as well as the Clinical Research Development Unit of the Rafsanjan University of Medical Sciences who helped us with this study. We would also like to thank all of patients for their cooperation in this research project. 


\section{Authors}

Maryam Shahpari

Critical care nursing student, Student Research Committee, School of Nursing and Midwifery, Rafsanjan University of Medical Sciences, Rafsanjan, Iran.

\section{Dr Shahin Heidari}

Assistant Professor, Department of Fundamental Nursing, School of Nursing and Midwifery, Geriatric Care Research Center, Rafsanjan University of Medical Sciences, Rafsanjan, Iran.

Dr. Tabandeh Sadeghi

Associate Professor, Department of Pediatric Nursing, School of Nursing and Midwifery, Non-Communicable Diseases Research Center, Rafsanjan University of Medical Sciences, Rafsanjan, Iran.

\section{Corresponding author}

Dr. Tabandeh Sadeghi

Associate Professor, Department of

Pediatric Nursing, School of Nursing and Midwifery, Non-Communicable Diseases Research Center, Rafsanjan University of Medical Sciences, Rafsanjan, Iran.

\title{
The effects of a telephone-based orientation program, delivered during the waiting time, on anxiety in patients undergoing coronary angiography
}

\begin{abstract}
Background

Anxiety is one of the consequences of hospitalisation for diagnostictherapeutic procedures, especially in coronary angiography. Studies have shown that interventions when patients are admitted to hospital can reduce anxiety but no research has been carried out on the effects of interventions before patients are admitted. This study aimed to investigate the effects of a telephone-based orientation program, delivered during the waiting time, on anxiety in patients undergoing coronary angiography.
\end{abstract}

\section{Materials and methods}

In this clinical trial, 70 patients who were candidates for coronary angiography in an urban region of Iran were selected and randomly assigned to the intervention and control groups. The control group received routine care. In contrast, the intervention group received an orientation program via telephone during the waiting time in the weeks leading up to the procedure, in addition to routine care. The data was collected using the Spielberger State-Trait Anxiety Inventory (STAI) to assess patient anxiety at the time of admission, one hour before angiography and two hours after the procedure.

\section{Results}

There was a significant difference between the two groups in the mean scores of anxiety at admission, one hour before angiography and two hours after the procedure. The mean score of anxiety was lower in the intervention group than in the control group.

\section{Conclusions}

A telephone-based orientation program could be used when patients are waiting to have the procedure as a strategy for reducing anxiety in patients undergoing coronary angiography.

\section{Introduction}

Angiography is a standard method for anatomical examination of coronary arteries and gathering information to make decisions about the need for medication, angioplasty or coronary artery bypass surgery?. Despite providing many benefits for diagnosing coronary artery disease, coronary angiography can lead to complications such as myocardial infarction, arrhythmia, vascular complications, hypersensitivity, inflammatory and haemodynamic problems, and haemorrhage, as well as fear and anxiety ${ }^{2}$. 
More than 82 per cent of patients undergoing this invasive procedure experience fear and anxiety about the procedure as well as the results of the diagnosis ${ }^{3}$. Half of these patients report that the fear, anxiety and uncertainty is worse than their chest pain. Pre-angiography anxiety is greater than pre-cardiac surgery anxiety, which could be due to a lack of preparation and preparedness prior to the procedure ${ }^{4,5}$.

The associated increase in epinephrine and norepinephrine concentrations in plasma, as well as the increase in the respiratory rate, heart rate, arterial blood pressure and myocardial oxygen consumption, put these cardiac patients at risk ${ }^{6,7}$. One of the primary responsibilities of a nurse is to maximise the physiological and mental health of the patients. In patients with cardiovascular disease, anxiety should be considered a predictive and influencing factor in the future effects of the disease and the treatment of anxiety should be considered part of overall treatment ${ }^{8,9}$.

Lack of knowledge and unfamiliarity with the angiography procedure are the most common causes of patient anxiety before the commencement of this procedure. Therefore, interventions to reduce anxiety are of considerable importance ${ }^{10,11}$. Enabling patients to become familiar with the angiography procedure as well as describing the procedure to patients are among the interventions that have been considered in various studies to reduce patient anxiety. The results of a study by Hanifi et al. showed that an orientation program reduced stress, anxiety and depression in patients undergoing angiography ${ }^{12}$. Similarly, according to the results of a study by Farsi et al., an orientation tour reduced anxiety in patients undergoing coronary angiography ${ }^{13}$. A study by Lattuca et

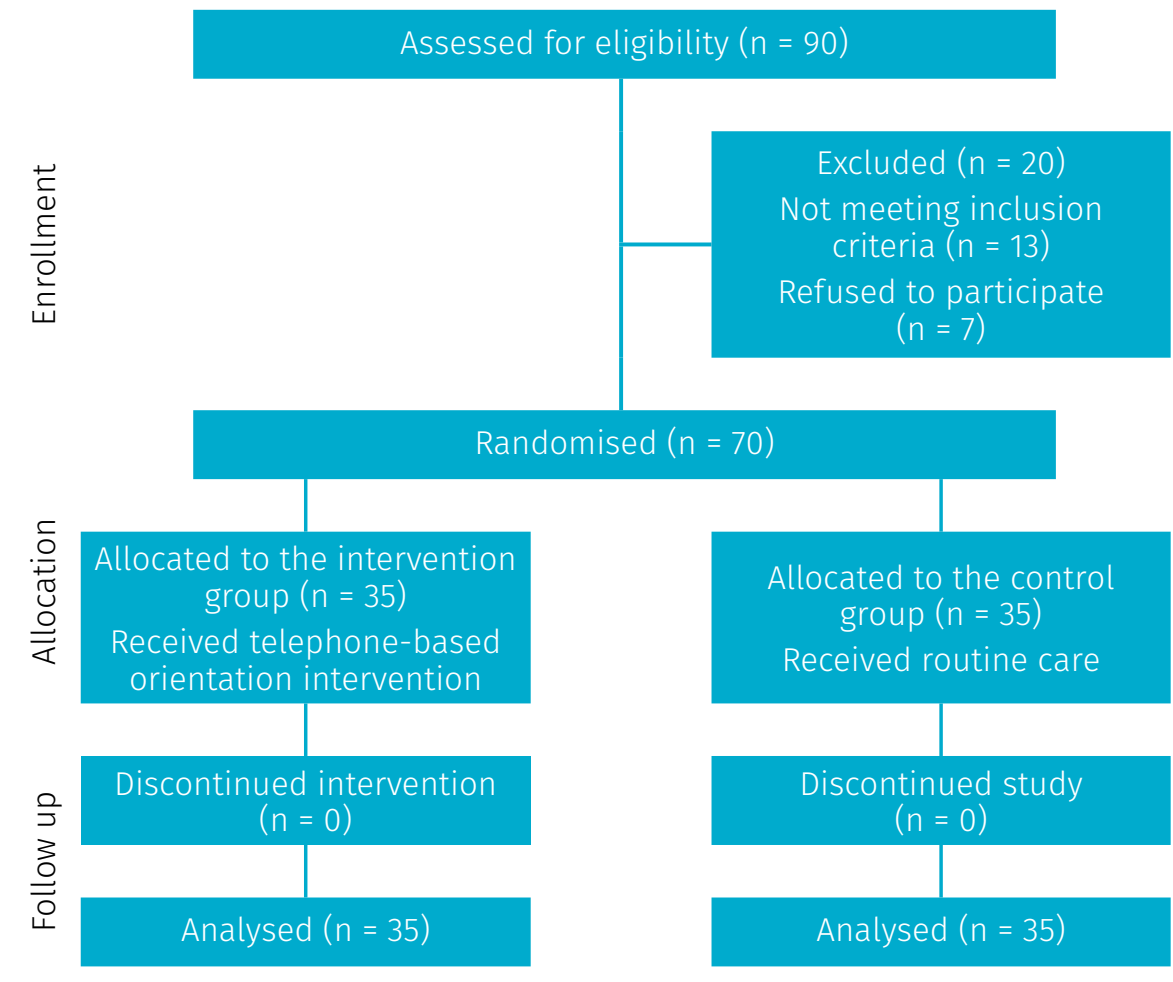

Figure 1: Consort flow diagram

al. also confirmed a positive effect on anxiety in patients undergoing angiography from watching educational videos at the time of admission $^{14}$.

All the above-mentioned studies involved interventions at the time of admission or hospitalisation and none of them considered intervention during the waiting time in the weeks leading up to a coronary angiography. During this time the patient may receive information from unreliable sources such as Wikipedia, blogs, tweets, personal websites and social media feeds and this could lead to an increase in anxiety. Telephone-based interventions could be helpful in such cases.

Telephone-based interventions are a useful and inexpensive method for assessing patient needs ${ }^{15}$. Based on various studies, providing essential education by telephone reduces readmission in patients after coronary artery bypass graft surgery ${ }^{16}$, reduces hospital admissions in patients with heart failure ${ }^{17}$ and increases the quality of life after myocardial infarction ${ }^{18}$. However, no studies have been conducted with patients on the waiting list for coronary angiography. Given the importance of this subject as well as the limited number of studies in this field, this study aims to investigate the effect of a telephone-based orientation program, delivered during the waiting time, on anxiety in patients undergoing coronary angiography.

\section{Materials and methods}

This study was a clinical trial registered at the Iranian Registry for Clinical Trials under code IRCT20150713023190N7. The research population included patients who were candidates for angiography and were on the waiting list in an urban region of Iran. The study sample size was estimated at 33 per group based on previous studies ${ }^{19}$. The level of significance was set at $p<0.05$, and 
the study power was estimated at 90 per cent. Given the possibility of sample dropout (5-10\%), 35 patients were allocated to each group. (See Figure 1 for a consort flow diagram of the two groups.)

Patients having angiography were included if they were 35 to 60 years old, not routinely taking sedatives, able to use a telephone, not cognitively impaired and had no history of mental illness and no prior history of angiography.

Seventy candidates for angiography were selected based on the inclusion criteria. They were assigned to the intervention and control groups using the categorisation and minimisation methods. In so doing, the participants were initially categorised based on confounding variables such as age and gender. Next, participants were placed in the intervention group or control group by a coin toss ${ }^{20}$. Written consent forms were obtained from the participants at the time of admission.

The data collection tools comprised a demographic questionnaire for participants (age, sex, education, marital status and duration of the disease) as well as the Spielberger State-Trait Anxiety Inventory (STAI). The reliability of the demographic questionnaire was verified by the content validity method as well as the opinions of professors and experts. The STAI is a commonly used measure of trait and state anxiety. The most popular version of the inventory form has 20 items for assessing trait anxiety and 20 items for assessing state anxiety. Internal consistency coefficients for the scale ranged from 0.86 to 0.95 , while test-retest reliability coefficients ranged from 0.65 to 0.75 over a twomonth interval ${ }^{21}$. In this study, only the state anxiety questions were used as they related to the patient's feelings at the time of filling in the questionnaire. Items were scored from 1 to 4, with total scores ranging from 20 to 80 .

In addition to routine care, patients in the intervention group received information by telephone in two 15-minute sessions, one the day after their appointment was made and another the day before their angiography. The telephone sessions included descriptions of the angiographic process and its duration, pre- and post-angiography preparation, time back to the ward, common nursing care for angiography patients, the method of communicating with doctors and nurses, time of discharge from the angiography ward, bed rest recommended after angiography, home care and hospitalisation. The content was the same in both sessions, but participants' questions were answered in the second session. Data was collected by one staff nurse of the angiography ward who was blinded to group allocation. Routine care included introducing the doctor, description of the angiography procedure and information about the duration of the procedure, time back to the ward and common nursing care for angiography patients. This routine care was the same in both groups.

The STAI instrument was completed through face-to-face interviews on admission, one hour before the angiography and two hours after. Data was analysed using descriptive statistics, such as mean and standard deviation, as well as analytical statistics, including independent t-test and repeated measures analysis of variance (ANOVA) using SPSS Statistics 18 software. The significance level was set at less than 0.05 .

\section{Ethical considerations}

Ethical considerations of this study included obtaining an ethics code from the ethics committee, obtaining written consent forms from the participants, briefing participants about the study and its goals, and keeping patient information confidential.

\section{Results}

The mean age of the participants in the intervention and control groups was $50.17 \pm 6.35$ and $49.48 \pm 11.02$ years, respectively. The population was homogeneous in terms of demographic characteristics (Table 1).

The normal distribution of data was confirmed using the KolmogorovSmirnov test $(p>0.05)$. There was a significant difference between the two groups on admission with the mean anxiety level lower in the intervention group than in the control group (t-test, $p<0.001$ ). Furthermore, there was a significant difference between the two groups one hour before angiography and two hours after angiography with the mean anxiety level being lower in the intervention group compared to the control group (t-test, $p<$ 0.001). Intra-group comparisons were made and interactive effects of the time and group were evaluated using the repeated measures ANOVA. Time exerted a significant effect $(p=0.001)$ and the interactive effects were also significant ( $p=0.006)$. Although the mean anxiety level one hour before angiography was higher than at admission in the two groups, the increase was lower in the intervention group than in the control group (see Table 2).

\section{Discussion}

The mean score of anxiety on admission was lower in the intervention group than in the 
Table1. Comparison of demographic characteristics of patients in the intervention and control groups

\begin{tabular}{|c|c|c|c|c|}
\hline Variable & & Control group & $\begin{array}{l}\text { Intervention } \\
\text { group }\end{array}$ & $p$-value \\
\hline Age (years) & mean \pm SD & $49.48 \pm 11.02$ & $50.17 \pm 6.35$ & $0.75={ }^{*} p$ \\
\hline $\begin{array}{l}\text { Duration of } \\
\text { disease (months) }\end{array}$ & mean \pm SD & $3.94 \pm 3.49$ & $4.02 \pm 2.94$ & $0.91={ }^{*} p$ \\
\hline $\begin{array}{l}\text { Duration of } \\
\text { angiography } \\
\text { (minutes) }\end{array}$ & mean \pm SD & $23.71 \pm 12.14$ & $22.17 \pm 11.20$ & $0.72={ }^{*} p$ \\
\hline \multirow{2}{*}{ Gender } & male (\%) & $18(51.4)$ & $21(60)$ & \multirow{2}{*}{$0.47={ }^{* *} p$} \\
\hline & female (\%) & $17(48.6)$ & $14(40)$ & \\
\hline \multirow{2}{*}{ Marital status } & married & $34(97.1)$ & $35(100)$ & \multirow{2}{*}{$1=p^{* \star *}$} \\
\hline & single & $1(2.9)$ & 0 & \\
\hline \multirow{3}{*}{ Educational level } & $\begin{array}{c}\text { under } \\
\text { diploma (\%) }\end{array}$ & $19(54.3)$ & $22(62.9)$ & \multirow{3}{*}{$0.93={ }^{* *} p$} \\
\hline & diploma (\%) & $12(34.3)$ & $11(31.4)$ & \\
\hline & $\begin{array}{c}\text { above } \\
\text { diploma (\%) }\end{array}$ & $4(11.4)$ & $2(5.7)$ & \\
\hline \multirow{2}{*}{$\begin{array}{l}\text { History of } \\
\text { hospitalisation }\end{array}$} & yes (\%) & $17(48.6)$ & $13(37.1)$ & \multirow{2}{*}{$0.33={ }^{* *} p$} \\
\hline & no $(\%)$ & $18(51.4)$ & $22(62.9)$ & \\
\hline
\end{tabular}

* Independent t-test

** Chi-square test

*** Fisher's exact test

Table 2. Comparison of mean anxiety level in patients of both groups before and after the procedure

\begin{tabular}{|c|c|c|c|c|}
\hline \multicolumn{2}{|l|}{ Time } & Control group & $\begin{array}{l}\text { Intervention } \\
\text { group }\end{array}$ & ${ }^{*} p$-value \\
\hline \multicolumn{2}{|l|}{$\begin{array}{l}\text { On admission } \\
\text { mean } \pm S D\end{array}$} & $42.97 \pm 8.49$ & $31.68 \pm 5.43$ & $<0.001$ \\
\hline \multicolumn{2}{|c|}{$\begin{array}{l}\text { One hour before angiography } \\
\text { mean } \pm S D\end{array}$} & $46.02 \pm 7.41$ & $34.57 \pm 5.33$ & $<0.001$ \\
\hline \multicolumn{2}{|c|}{$\begin{array}{l}\text { Two hours after angiography } \\
\text { mean } \pm S D\end{array}$} & $33.40 \pm 4.22$ & $25.34 \pm 2.80$ & $<0.001$ \\
\hline \multirow{2}{*}{$\begin{array}{l}\text { Repeated } \\
\text { measure ANOVA }\end{array}$} & ** p-value & & 0.001 & \\
\hline & $* * * p$-value & & 0.006 & \\
\hline
\end{tabular}

* Independent t-test

** Repeated measure ANOVA (intra-group comparison)

*** Repeated measure ANOVA (interactive effect) control group. This result is different to the results of the studies by Farsi et al.13 and Hanifi et al.12 who found no significant difference in the mean anxiety scores between groups on admission. In contrast, the results of a study by Abolghasemi and Akbari22 were similar to our findings indicating that familiarity with the procedure decreased patient stress and anxiety.

From a psychological perspective, ambiguity about the causes of past or future events is the source of human concern, which leads to anxiety. Therefore, anything that reduces this ambiguity and increases clarity regarding future events will have an impact on reducing anxiety ${ }^{23}$. As was observed in this study, patient familiarity with the procedure reduces anxiety, so we would suggest it as a useful intervention.

According to our results, patient anxiety increased one hour before angiography in both groups. A study conducted by Whitehead et al. on anxiety and quality of life in patients undergoing coronary angiography showed similar results, finding that the closer the patient was to angiography the more anxious they were ${ }^{24}$.

In the present study, the increase in the anxiety level one hour before angiography was less in the intervention group than in the control group and there was a statistically significant difference between the two groups. The results of a study by Varaei et al..$^{25}$ are consistent with these findings. They found that familiarising patients to angiography with a pre-procedural visit one day before had a significant effect on reducing stress one hour before angiography. The results of a study by Gross et al., who used a telephone counselling program during the waiting time for patients undergoing kidney transplantation, 
were comparable to our findings, showing that a telephone support program can reduce stress and increase patient satisfaction ${ }^{26}$. However, in contrast, Talaei et al. concluded that an orientation program did not reduce anxiety. In this study, the authors conducted an orientation program a day before tubectomy surgery and found no reduction in anxiety half an hour before surgery ${ }^{27}$. There were differences in the study population and the type of intervention, however, which may explain the contrasting results.

According to our study results, the mean anxiety score decreased in both groups two hours after angiography but the decrease was more significant in the intervention group than in the control group. The results of a study by Yan et al. which used telephone follow-up intervention were similar to our findings, showing that interventions improved self-esteem, physical activity and nutrition among patients ${ }^{18}$. In contrast, the results of a study by Hanssen et al. found that a telephone follow-up of patients with acute myocardial infarction did not significantly improve their quality of life compared to the control group, but it did improve the quality of life in patients aged over 70 years ${ }^{28}$. According to the results of a study by Jerant et al. the costs of treatment in the telephone intervention group were over 80 per cent lower than those in the control group, and the number of referrals to the hospital was three times less than in the control group ${ }^{17}$.

The results of this study and most of the aforementioned studies show that telephone-based interventions can reduce patient anxiety. Limitations of this study include the fact that it was conducted at one centre only. It also did not collect data on all excluding variables, such as physiological indicators. Conducting similar studies at other centres and assessing other variables, such as patient satisfaction after receiving telephone-based interventions, is recommended.

\section{Conclusion}

The results of this study show that a telephone-based orientation program, delivered during the waiting time, can decrease anxiety before and after coronary angiography. Therefore, this intervention is recommended for nurses to support patients in managing their anxiety related to planned medical interventions.

\section{Conflict of interest}

None declared.

\section{References}

1. Wilcoxson VL. Early ambulation after diagnostic cardiac catheterization via femoral artery access. I Nurse Pract 2012;8(10):810-815.

2. Trotter R, Gallagher R, Donoghue J. Anxiety in patients undergoing percutaneous coronary interventions. Heart Lung 2011;40(3):185-192.

3. Adib Hajbaghery M, Moradi T, Mohseni R. Effects of a multimodal preparation package on vital signs of patients waiting for coronary angiography. Nurs Midwif Stud 2014;3(1):e17518.

4. Nekouei ZK, Yousefy A, Manshaee G, Nikneshan S. Comparing anxiety in cardiac patients candidate for angiography with normal population. ARYA Atheroscler 2011;7(3):93-96.

5. Shaw LJ, Shaw RE, Merz CN, Brindis RG, Klein LW, Nallamothu B et al. Impact of ethnicity and gender differences on angiographic coronary artery disease prevalence and inhospital mortality in the American College of Cardiology-National Cardiovascular Data Registry. Circulation 2008;117(14):1787-1801.

6. Mikosch P, Hadrawa T, Laubreiter K, Brandl J, Pilz J, Stettner $\mathrm{H}$ et al. Effectiveness of respiratory-sinus-arrhythmia biofeedback on state-anxiety in patients undergoing coronary angiography. J Adv Nurs 2010;66(5):1101-1110.
7. Rejeh N, Heravi-Karimooi M, Tadrisi SD, Jahani A, Vaismoradi M, Jordan S. The impact of listening to pleasant natural sounds on anxiety and physiologic parameters in patients undergoing coronary angiography: A pragmatic quasi-randomized-controlled trial. Complement Ther Clin Pract 2016; 25:42-51.

8. Pouyesh V, Amaniyan S, Haji Mohammad Hoseini M, Bashiri Y, Sieloff C, Griffiths P et al. The effects of environmental factors in waiting rooms on anxiety among patients undergoing coronary angiography: A randomized controlled trial. Int I Nurs Pract 2018;24(6):e12682

9. Lieber AC, Bose J, Zhang X, Seltzberg $H$, Loewy J, Rossetti A et al. Effects of music therapy on anxiety and physiologic parameters in angiography: A systematic review and meta-analysis. J Neurolntervent Surg 2019;11:416-423.

10. Liddle C. Preparing patients to undergo surgery. Nurs Times 2012;108(48):12-13.

11. Su SF, Liao YC, Wu MS. Age and pain as predictors of discomfort in patients undergoing transfemoral percutaneous coronary interventions. Heart Lung 2018;47:576-583.

12. Hanifi N, Bahraminejad N, MirzaeeT, Ahmadi F, Khani M, Taran L. The effect of orientation program on stress, anxiety and depression of patients undergoing coronary angiography. Iran J Nurs Res 2012; 7(25):1-8.

13. Farsi Z, Sajadi SA, Eslami R. Effects of peer education and orientation tour on anxiety in patient candidates for coronary angiography. Nurs Midwif Stud 2016;5(3):e31624.

14. Lattuca B, Barber-Chamoux N, Alos B, Sfaxi $A$, Mulliez A, Miton $N$ et al. Impact of video on the understanding and satisfaction of patients receiving informed consent before elective inpatient coronary angiography: A randomized trial. Am Heart J 2018;200:67-74

15. Oh J-Y, Park Y-T, Jo EC, Kim S-M. Current status and progress of telemedicine in Korea and other countries. Healthc Inform Res 2015;21(4):239-243.

16. Forouzesh M, Sanagoo A, Vakili MA, Jouybari L. The effect of telenursing (telephone follow up) after discharge on readmission due to complications after coronary artery bypass graft surgery. Journal of Urmia Nursing and Midwifery Faculty 2017;15(8):584-594.

17. Jerant AF, Azari R, Martinez C, Nesbitt TS. A randomized trial of telenursing to reduce hospitalization for heart failure: Patientcentered outcomes and nursing indicators. Home Health Care Serv Q 2003;22(1):1-20. 
18. Yan J, You L-m, Liu B-l, Jin S-y, Zhou J-j, Lin $\mathrm{C}-\mathrm{x}$ et al. The effect of a telephone followup intervention on illness perception and lifestyle after myocardial infarction in China: A randomized controlled trial. Int J Nurs Stud 2014; 51(6):844-855.

19. Mobini-Bidgoli M, Taghadosi M, Gilasi H, Farokhian A. The effect of hand reflexology on anxiety in patients undergoing coronary angiography: A single-blind randomized controlled trial. Complement Ther Clin Pract 2017;27:31-36.

20. Pandis N, Switzerland B, Greece C. Randomization. Part 2: Minimization. Am J Orthod Dentofacial Orthop 2011;140: 902-904.

21. Spielberger CD, Gorsuch RL, Lushene R, Vagg $P R$, Jacobs GA. Manual for the state-trait anxiety inventory. Palo Alto: Consulting Psychologists Press; 1983.
22. Abolghasemi L, Akbari B. Effects of awareness raising program on the stress, anxiety and improvement of exercise performance in patients undergoing cardiovascular diagnostic examination. Journal of Guilan University of Medical Sciences 2018; 27(106):23-31.

23. Clark DA, Beck AT. Cognitive Therapy of Anxiety Disorders: Science and Practice. New York: Guilford Press; 2010.

24. Whitehead NJ, Clark AL, Williams TD, Collins NJ, Boyle AJ. Sedation and analgesia for cardiac catheterization and coronary intervention. Heart Lung Circ 2020;29(2):169177.

25. Varaei S, Keshavarz S, Nikbakhtnasrabadi A, Shamsizadeh M, Nejad AK. The effect of orientation tour with angiography procedure on anxiety and satisfaction of patients undergoing coronary angiography. Iran J Psychiatr Nurs 2013;1(2):1-10
26. Gross CR, Reilly-Spong M, Park T, Zhao R, Gurvich OV, Ibrahim HN. Telephoneadapted mindfulness-based stress reduction (tMBSR) for patients awaiting kidney transplantation. Contemp Clin Trials 2017;57:37-43.

27. Talaei A, Toufani H, Hojjat SK, Jami-Alahmadi Z. Effect of familiarizing the patient with the personnel and operating room on the day before surgery for preoperative anxiety. Quarterly Journal of Fundamentals of Mental Health 2004; 6(21-22): 57-61.

28. Hanssen TA, Nordrehaug JE, Eide GE, Hanestad BR. Does a telephone follow-up intervention for patients discharged with acute myocardial infarction have long-term effects on health-related quality of life? A randomized controlled trial. J Clin Nurs 2009;18(9):1334-1345. 